\title{
Prevalence of central and peripheral neuropathic pain in patients attending pain clinics in Spain: factors related to intensity of pain and quality of life [Corrigendum]
}

\author{
Failde I, Dueñas M, Ribera MV, Gálvez R, Mico JA, Salazar
}

A, de Sola H, Pérez C. J Pain Res. 2018;11:1835-1847.

Page 1839, Figure 1, the authors have advised the figure is incorrect. The correct figure is shown below.

Diagnostic label

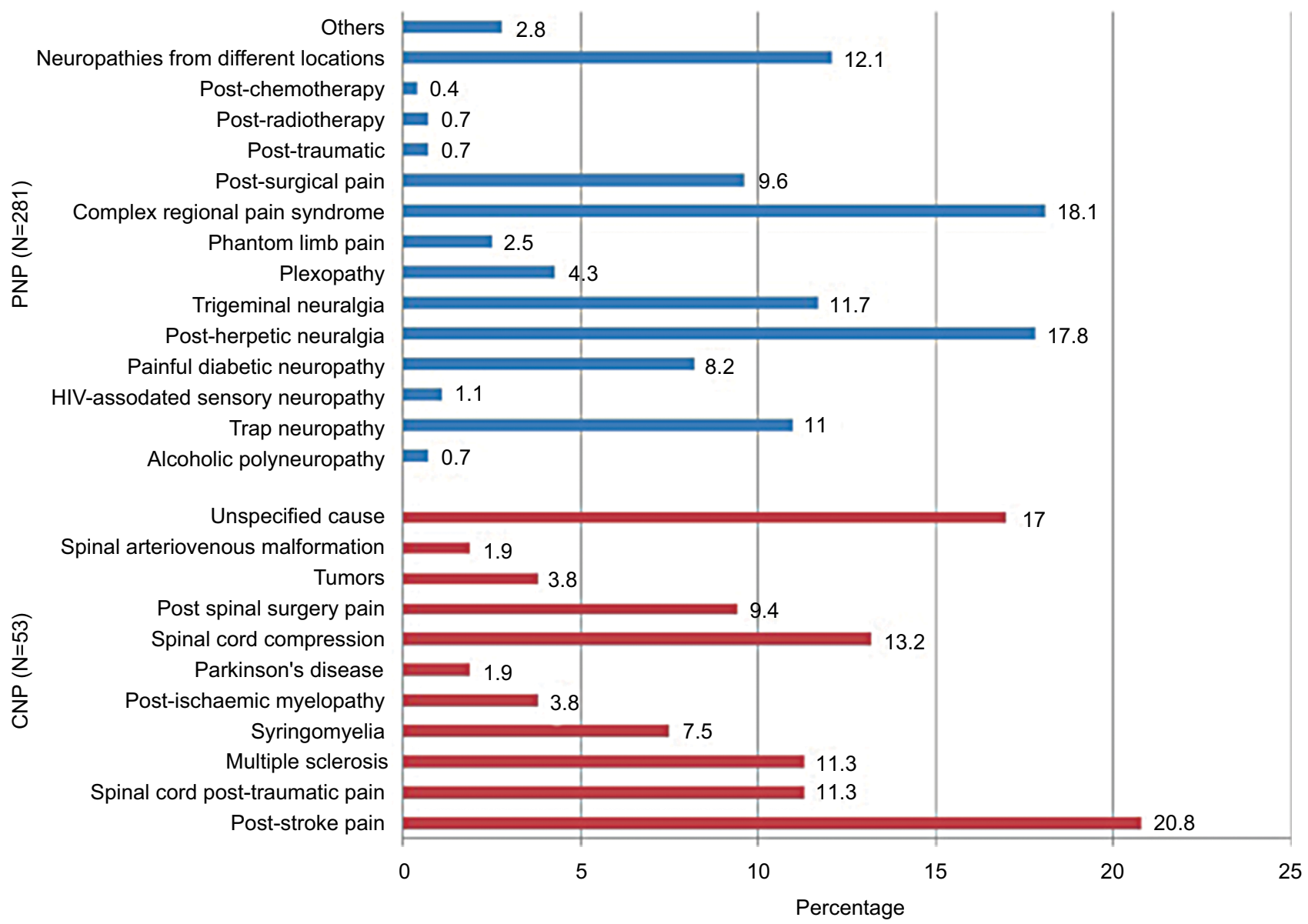

Journal of Pain Research

\section{Publish your work in this journal}

The Journal of Pain Research is an international, peer reviewed, open access, online journal that welcomes laboratory and clinical findings in the fields of pain research and the prevention and management of pain. Original research, reviews, symposium reports, hypothesis formation and commentaries are all considered for publication. 